\title{
SISTEM PENYIRAMAN TANAMAN HIAS OTOMATIS DENGAN METODE C4.5 BERBASIS IOT (Internet of Things)
}

\author{
Rian Hermawan ${ }^{* 1}$, Gilang Handika Adji ${ }^{\# 2}$ \\ Program Studi Teknik Informatika, STMIK Subang \\ Jl. Marsinu No. 5 - Subang, Tlp. 0206-417853 Fax. 0206-411873 \\ E-mail: stmik.rian@yahoo.com ${ }^{* 1}$, handikag61@gmail.com ${ }^{\# 2}$
}

\begin{abstract}
ABSTRAKSI
Tanaman merupakan tumbuhan yang dibudidayakan agar dapat diambil manfaatnya. Budidaya tanaman sendiri pada dasarnya dapat menjadi peluang usaha yang menjanjikan. Mulai dari budidaya tanaman hias, sayur mayur dan lain sebagainya. Tetapi saat ini produksi tanaman hias masih banyak yang belum menghasilkan hasil yang maksimal, dikarenakan masyarakat masih menggunakan teknologi manual dalam sistem pertanian yang digunakan. Tujuan dilakukan penelitian ini adalah merancang sebuah alat penyiraman tanaman hias otomatis untuk mengatasi masalah dalam penyiraman tanaman hias yang masin dilakukan secara manual dan sebagai bahan pembelajaran. Prototype ini menggunakan Arduino Uno sebagai pengontrol utama, sensor kelembaban tanah digunakan untuk membaca kadar kelembaban tanah dan digunakan sebagai saklar untuk menghidupkan pompa penyiram.

Sistem pengambilan ini mengambil data dengan sensor kelembaban tanah, kelembaban udara, dan suhu, untuk mencari kelembaban tanah, kelembaban udara dan suhu pada tanaman. Kemudian data yang diperoleh di kirim ke jaringan modul ESP8266 dan dikirim ke platform thingspeak, data yang tampil di inputkan ke dalam databse untuk diolah menggunakan metode C4.5, hasil perhitungan ke dalam database untuk diolah menggunakan metode C4.5, hasil perhitungan ditampilkan oleh sistem.
\end{abstract}

\section{Kata Kunci : Arduino Uno, IoT, C4.5}

\section{Pendahuluan}

\subsection{Latar Belakang}

Tanah merupakan salah satu media yang digunakan sebagai media hidup dari berbagai macam tumbuhan. Tanaman memerlukan air untuk dapat tumbuh secara optimal. Untuk itulah kondisi kelembaban tanah harus dijaga pada suatu keadaan tertentu yang sesuai dengan kebutuhan tanaman. Kekurangan kadar air atau kelebihan kadar air dapat mengakibatkan tanaman tidak dapat tumbuh dengan baik. Oleh karena itu, diperlukan suatu sistem yang bekerja secara otomatis dan cerdas untuk melakukan penyiraman tanaman. Sistem ini akan menjaga kadar air pada tanah yang sesuai dengan kebutuhan tanaman. Kondisi kadar air tanah diperoleh dari sensor kelembaban tanah dan dipengaruhi juga oleh suhu udara.

Dalam kasus ini Mikrokontroler dapat membantu tugas manusia dalam melakukan penyiraman dan monitoring pada tanaman, yang biasanya dilakukan dengan cara manual. Cara kerja Mikrokontroler ini cukup mudah hanya dikendalikan lewat website.

\subsection{Identifikasi Masalah}

Berdasarkan latar belakang diatas,maka dapat diidentifikasi beberapa permasalahan sebagai berikut:

1. Keterbatasannya indra manusia unutk mengontrol kelembaban tanah pada tanaman.

2. Kekurangan air pada tanaman yang membuat tanaman akan menjadi layu.

3. Kelebihan air pada tanaman membuat permukaan tanah lembab yang memunculkan mikroorganisme jamur yang menyebabkan penyakit bagi tanaman. 


\subsection{Tujuan}

Tujuan yang dipeoleh dari penelitian ini :

1. Membuat alat yang murah dengan tingkat keakuratan tinggi.

2. Menerapkan IoT sebagai sistem pendukung keputusan penyiraman tanaman hias.

3. Membuat alat yang dapat mendeteksi kelembaban tanah, kelembaban udara, dan suhu udara.

\subsection{Manfaat}

Manfaat yang dapat diperoleh dari hasil penelitian tugas akhir ini adalah :

1. Merancang dan mengimplementasikan sebuah sistem cerdas yang dapat digunakan untuk penyiraman otomatis pada tanaman.

2. Menghemat waktu dalam melakukan penyiraman tanaman.

3. Menambahkan suatu pengalaman dalam menstransformasikan ilmu pengetahuan dan teknologi menjadi suatu media, ataupun barang yang canggih dan efisien.

\subsection{Batasan Masalah}

Berdasarkan rumusan masalah di atas, maka dalam penyusunan laporan penelitian ini penulis membatasi pembahasan hanya pada :

1. Merancang sistem penyiraman tanaman hias otomatis dengan menggunakan beberapa alat diantaranya: sensor soil moisture, sensor suhu DHT 11, kabel jumper, breadboard, Arduino Uno dan ESP8266.

2. Sistem pemantauan kelembaban tanah hanya memberikan keterangan proses untuk menyiram tanaman secaara otomatis, tidak membahas pertumbuhan tanaman.

3. Sistem yang di bangun memakai bahasa pemrograman arduino uno, dan platform Thinkspeak.

4. Metode yang akan di gunakan adalah metode C4.5.

\subsection{Metodologi Penelitian}

Pada penelitian ini menggunakan metode deskriptif, yaitu metode yang menggambarkan suatu keadaan atau permasalahan yang sedang terjadi berdasarkan fakta dan data-data yang diperoleh dan dikumpulkan pada waktu pelaksanaan penelitian. Berdasarkan hasil yang dilakukan, maka dapat ditetapkan menjadi rumusan masalah, kemudian dibuat batasan-batasan masalah agar pembahasan yang akan dijelaskan tidak keluar dari ruang lingkup penelitian.

1. Studi Literatur

Yaitu pengambilan pustaka yang relevan dengan topik utama yang dikaji, sehingga memperoleh landasan teoritik untuk melakukan rancang bangun.

2. Metode pengumpulan data

Yaitu metode pengumpulan data dan referensi dari media cetak elektronik yang menunjang dalam penyusunan tugas akhir.

3. Metode observasi

Yaitu pengumpulan data dengan cara melakukan pengamatan langusng terhadap alat dan aplikasi yang akan di buat.

4. Pengumpulan alat dan bahan

Dalam metode ini dilakukan pengumpulan alat dan bahan pokok seperti komputer server, mikrokontroler dengan pendukungnya.

5. Melakukan pengujian terhadap tiap komponen dengan alat uji yang sesuai.

Perancangan dan realisasi tiap blok sesuai dengan diagram skema yang telahditentukan.

\section{Tinjauan Pustaka}

\subsection{Penyiraman Tanaman}

Penyiraman merupakan suatu hal yang tidak dapat dilepaskan didalam menjaga serta merawat tanaman agar tanaman tetap tumbuh dengan subur. Kebutuhan air yang cukup sangat mempengaruhi pertumbuhan tanaman. Contohnya seperti tanaman cabai dan tomat yang membutuhkan perhatian khusus karena jika tanaman ini tidak mendapatkan kondisi yang baik maka tanaman tidak dapat tumbuh dengan baik, bahkan akan berdampak fatal bagi tanaman tersebut. [1] 
Penyiraman tanaman secara manual dapat mengganggu efisiensi waktu dan tenaga. Penyiraman pada tanaman dengan kelebihan atau kekurangan air dapat pula mengurangi daya tahan maupun menyebabkan kematian pada tanaman itu sendiri. Sehingga berpotensi kerugian pada petani tanaman. [2]

\subsection{Mikrokontroler}

Mikrokontroler merupakan suatu bagian elektronik yang dalam wujudnya seperti IC (Integrated Circuit) yang dapat berguna sebagai komputer tetapi dalam ukuran yang kecil atau minim. Kata Mikrokontroler ini ialah gabungan dari dua kata yaitu Mikro dan Controler. Mikro berarti yang sangat kecil, sedangkan controler berarti sebuah pengendali. [3]

Mikrokontroler terdapat keunggulan tersendiri yaitu tersedia sebuah RAM dan peralatan I/O pendukung yang membuat ukuran board mikrokontroler ini menjadi lebih praktis. Mikrokontroler merupakan suatu chip pada komputer yang memilki fungsi untuk pengontrol susunan dari alat elektronik dan secara garis besar dapat menyimpan program yang ada. Mikrokontroler terbagi atas Memori, I/O khusus, ROM, Timers (pewaktu), dan unsur pendukung seperti ADC atau (Analog Digital Converter) yang sudah terjamin pada isi dalamnya.

\subsection{Arduino Uno}

Arduino Uno R3 adalah board sistem minimum berbasis mikrokontroller ATmega328P jenis AVR. Arduino Uno R3 memiliki 14 digital input/output (6 diantaranya dapat digunakan untuk PWM output), 6 analog input, $16 \mathrm{MHz}$ osilator kristal, USB connection, power jack, ICSP header dan tombol reset. [4]

\subsection{Unified Modeling Language (UML)}

Unified Modelling Language (UML) adalah sebuah bahasa yg telah menjadi standar dalam industri untuk visualisasi, merancang dan mendokumentasikan sistem piranti lunak. UML menawarkan sebuah standar untuk merancang model sebuah sistem.

Seperti bahasa-bahasa lainnya, UML mendefinisikan notasi dan syntax/semantik. Notasi UML merupakan sekumpulan bentuk khusus untuk menggambarkan berbagai diagram piranti lunak. Setiap bentuk memiliki makna tertentu, dan UML syntax mendefinisikan bagaimana bentuk-bentuk tersebut dapat dikombinasikan. Notasi UML terutama diturunkan dari 3 notasi yang telah ada sebelumnya: Grady Booch OOD (Object-Oriented Design), Jim Rumbaugh OMT (Object Modeling Technique), dan Ivar Jacobson OOSE (Object-Oriented Software Engineering).

Sejarah UML sendiri cukup panjang. Sampai era tahun 1990 seperti kita ketahui puluhan metodologi pemodelan berorientasi objek telah bermunculan di dunia. Diantaranya adalah: metodologi booch, metodologi coad, metodologi OOSE, metodologi OMT, metodologi shlaermellor, metodologi wirfs-brock, dsb. Masa itu terkenal dengan masa perang metodologi (method war) dalam pendesainan berorientasi objek. Masing-masing metodologi membawa notasi sendirisendiri, yang mengakibatkan timbul masalah baru apabila kita bekerjasama dengan group/perusahaan lain yang menggunakan metodologi yang berlainan. [5]

\section{Analisa}

\subsection{Deskripsi Sistem}

Pada Penelitian ini, penulis melakukan rancangan bangun sistem untuk pengujian penyiraman otomatis tanaman hias berbasis Iot pada platform Thingspeak menggunakan metode C4.5. Sistem ini merupakan perpaduan antara perangkat keras dan perangkat lunak yang saling terhubung dan telah deprogram. Perangkat keras yang di pakai yaitu Arduino R3, ESP01, sensor Soil Moisture, Sensor DHT-11, dan komponen lainnya. Sedangkan perangkat lunak yang digunakan yaitu platform thingspeak yang merypakan tempat penyimpanan data.

Sistem ini adalah untuk pengujian sebuah tanaman hias untuk mengetahui kelembaban tanah, kelembaban udara, dan suhu yang ada di sekitar tanaman hias. Untuk menjalankan sistem ini membutuhkan daya listrik dan koneksi jaringan Wireless unutk menghubungkan alat ke platform. Jaringan yang digunakan oleh laptop harus sama dengan jaringan yang di pakai oleh ESP01. 


\subsection{Analisis Kebutuhan Perangkat Keras}

Berdasarkan studi literature yang telah dilakukan, penulis menentukan beberapa komponen perangkat keras yang dibutuhkan untuk merangcang bangun sistem. Perangkat keras yang dimaksud adalah sebagai berikut :

- Arduino Uno R3

- Sensor Soil Moisture

- Sensor DHT-11

- $\quad$ Project Board

- $\quad$ ESP 8266

- Water Pump

- $\quad$ Kabel Jumper

Komputer Server, Komputer Server yang digunakan oleh penulis adalah laptop dengan spesifikasi processor Intel Core I5, RAM 4GB.

\subsection{Analisis Kebutuhan Perangkat Lunak}

Penulis telah melakukan analisa terhadap kebutuhan perangkat lunak yang diperlukan untuk melakukan rancang bangun sistem. Perangkat lunak yang dibutuhkan adalah sebagai berikut:

- Arduino IDE, berperan sebagai tempat program Arduino Uno R3, Sensor Soil Moisture, ESP 8266, dan komponen hardware lainnya yang dipakai dalam penelitian ini.

- $\quad$ Platform thingspeak, yang dibutuhkan sebagai penyimpanan data untuk penelitian ini.

- $\quad$ Sistem Operasi Windows.

\subsection{Perancangan Perangkat Keras}

Pada gambar ini merupakan rancangan alat atau skematik beserta sensor-sensor yang di sambungkan dengan alat-alat yang lainnya.

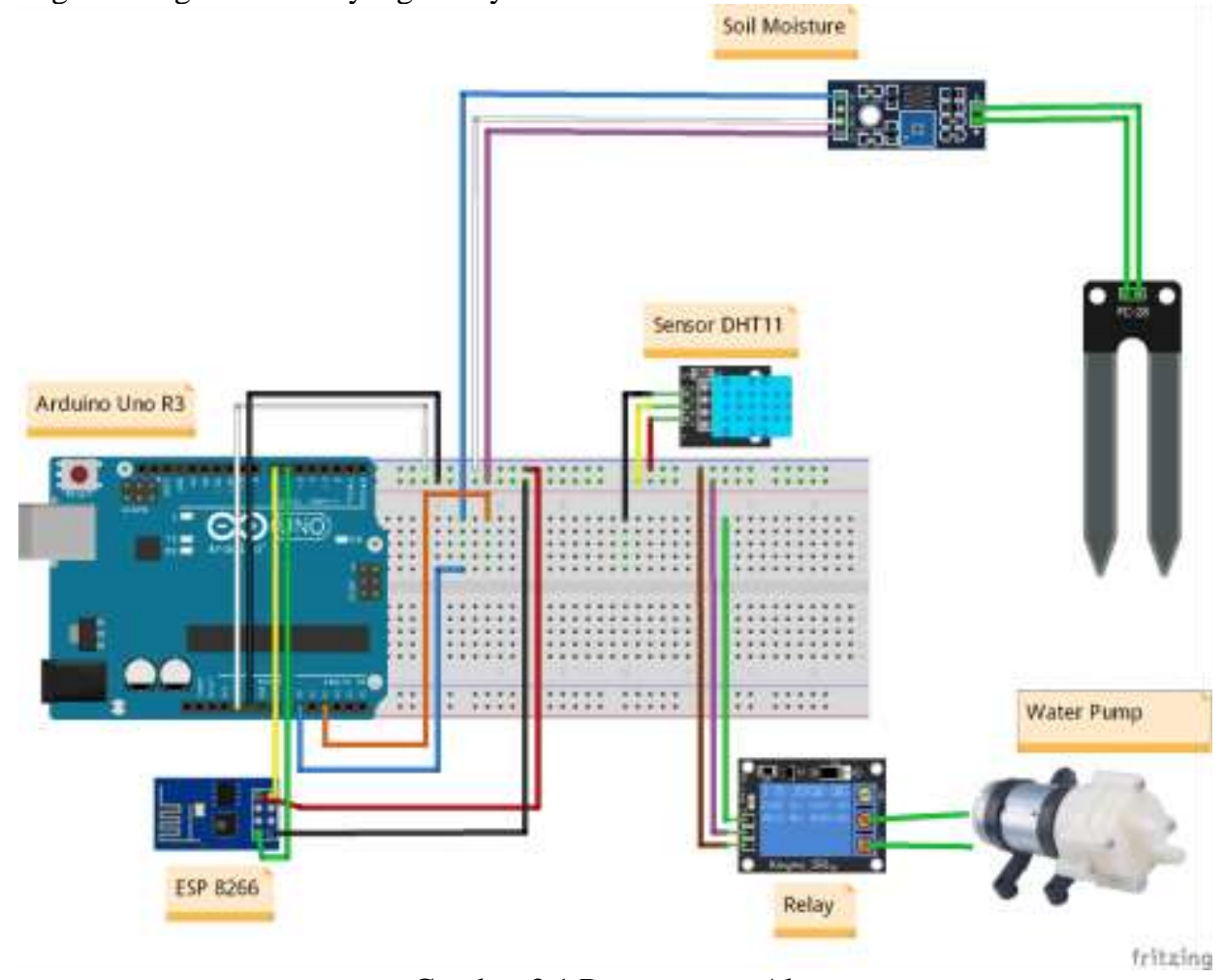

Gambar 3.1 Perancangan Alat 


\subsection{Software Requirement}

Software requirement merupakan suatu statement yang dijelaskan tenetang berbagai kebutuhan yang harus dipenuhi oleh suatu software. Software requirement dibuat atas dasar hasil proses analisa agar mempermudah proses pengembangan perangkat lunak. Berikut requirement hasil analisis penulis :

1. Sistem ini memungkinkan sensor untuk membaca data parameter.

2. Sensor Soil Moisture dapat membaca data kelembaban tanah.

3. Sensor DHT11 dapat membaca data kelembaban dan suhu.

4. Sistem ini dapat membaca data kemudian ke Cloud dengan modul WIFI ESP8266.

5. Data dapat disimpan dan ditampilkan di Cloud melalui platform yang digunakan.

6. Data di Cloud dapat di export ke dalam bentuk Excel.

7. Sistem ini dapat menyimpan data di databse yang terkoneksi ke WEB.

8. Sistem ini dapat melakukan perangkingan data dengan metode C4.5.

9. WEB memungkinkan dapat melakukan pengujian data parameter dengan metode $\mathrm{C} 4.5$

10. User dapat melakukan edit dan hapus data uji parameter yang telah di inputkan.

\subsection{Use Case Diagram} hias.

Perancangan use case Diagram mendeskripsikan proses operasi sistem penyiraman tanaman

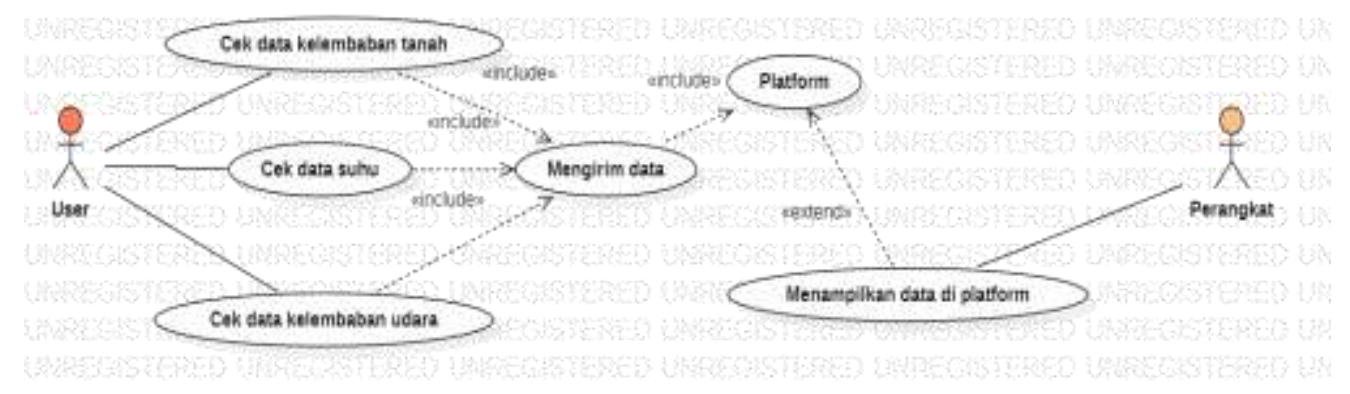

Gambar 3.2 Use Case Diagram

Penjelasan use case diagram :

1. Sistem mengirim data ke Thingspeak.

2. Sistem menampilkan data objek yang di terima dari Thingspeak.

3. User melihat data objek yang di tampilkan oleh sistem.

4. User menyimpan data objek pada database Thingspeak.

\subsection{Robustness Diagram}

Penulis membuat robustness diagram untuk menampilkan gambaran objek untuk setiap use case yang berinteraksi dengan system. 


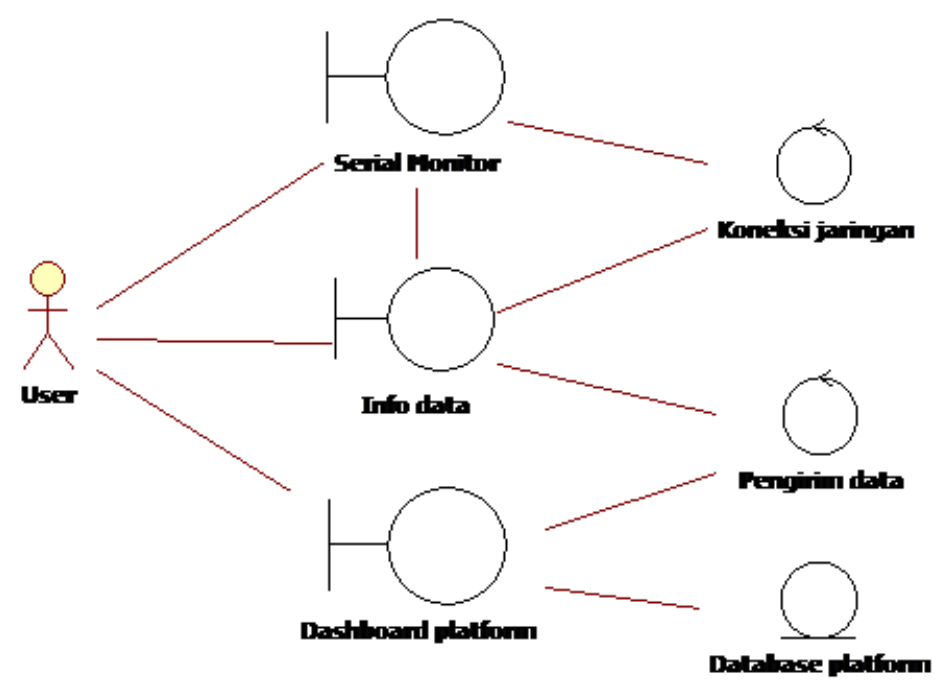

Gambar 3.3 Robustness Diagram

1. User melihat serial monitor untuk mengetahui sistem itu berjalan.

2. Sistem menyambungkan koneksi internet.

3. User melihat data sensor melalui serial monitor.

4. Sistem mengirim data ke platform.

5. User melihat hasil data sensor melalui platform.

6. Data sensor masuk databse platform.

\subsection{Sequence Diagram}

Penulis membuat sequence diagram untuk menggambarkan suatu diagram yang memperlihatkan atau menampilkan interaksi-interaksi antar objek didalam sistem.

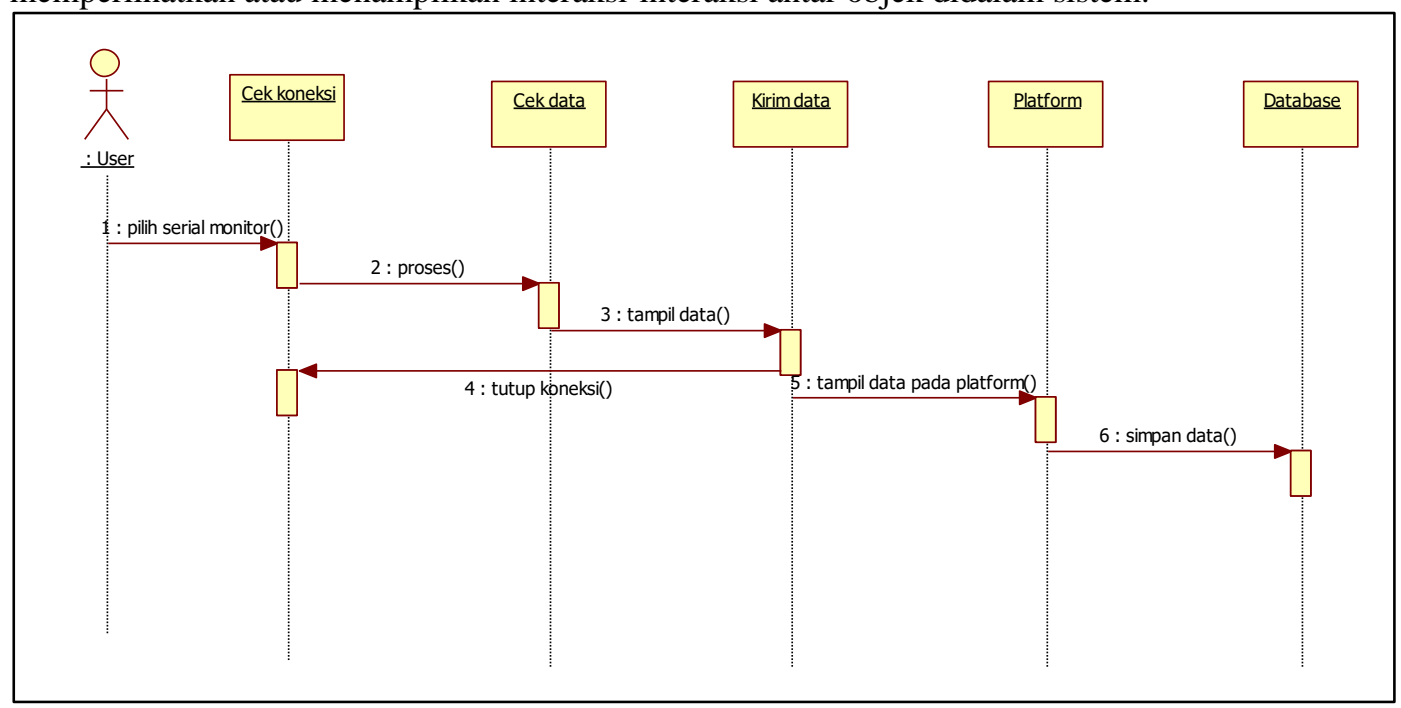

Gambar 3.4 Sequence Diagram

1. User membuka serial monitor.

2. Menyambungkan jaringan internet.

3. Menampilkan data serial monitor.

4. Jika koneksi terputus kemnali ke serial monitor dan coba menyambungkan ulang jaringan internet. 
5. Berhasil mengirim data ke platform dan menampilkan dara sensor.

6. Lalu menyimpan data sensor di database platform.

\subsection{Statechart Diagram}

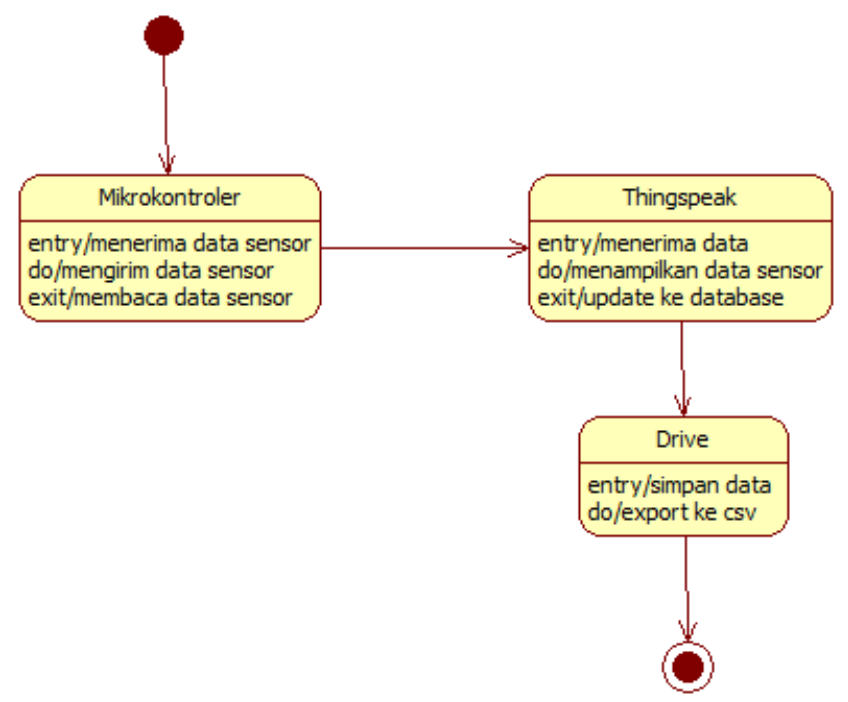

Gambar 3.5 Statechart Diagram

Sistem menghubungkan jaringan untuk mengirim data sensor, jika jaringan terputus maka sistem tidak akan mengirim data ke platform dan akan mengecek ulang jaringan. Kemudian jika jaringan terhubung dengan baik maka data sensor di platform dan tersimpan otomatis oleh database platform.

\subsection{Activity Diagram}

Penulis membuat activity diagram untuk menampilkan aliran aktivitas dalam sebuah sistem yang dirancang.

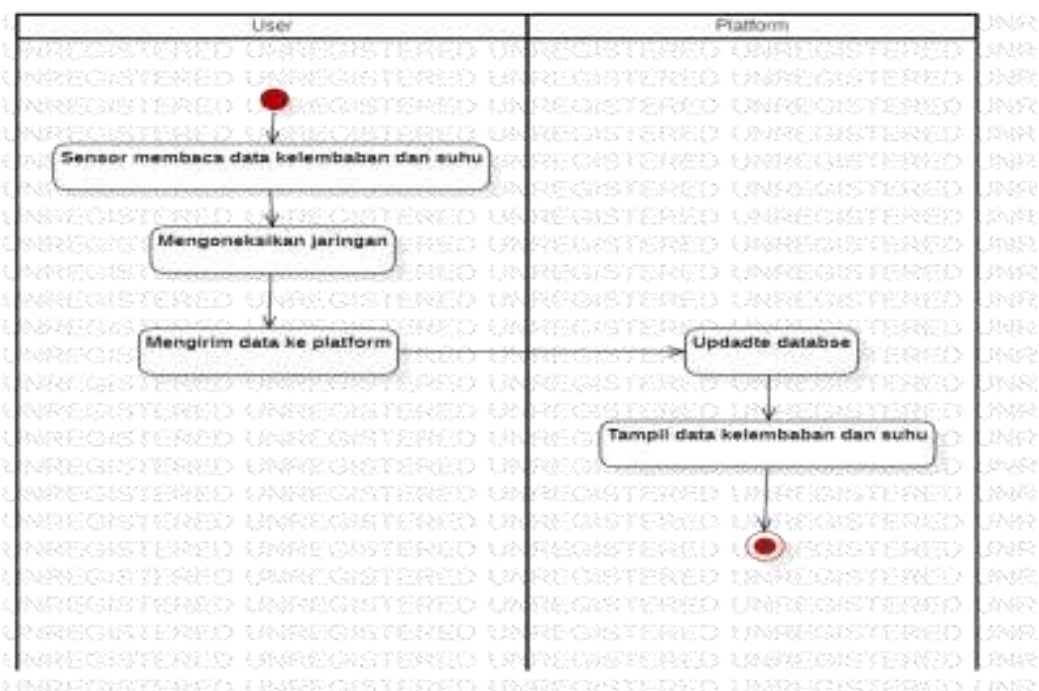

Gambar 3.6 Activity Diagram 
Alat dihidupkan, kemudian alat terhubung dengan haringan, jika jaringan tidak terhubung (tidak ditemukan) maka alat akan menghubungkan kembali ke jaringan samoai terhubung. Setelah alat terhubung ke jaringan maka alat akan menghubungkan ke Thingspeak, setelah terhubung ke Thingspeak maka data dari sensor di kirimi ke Thingspeak untuk ditampilkan di dashboard Thingspeak. Databse akan mengupdate sendiri ketika data sensor itu terkirim.

\subsection{Class Diagram}

Class Diagram adalah visual dari jenis yang dibentuk. Class diagram merupakan jalur jalannya database pada seluruh sistem yang digunakan untuk menampilkan beberapa kelas yang ada dalam sistem perangkat lunak yang akan dikembangkan.

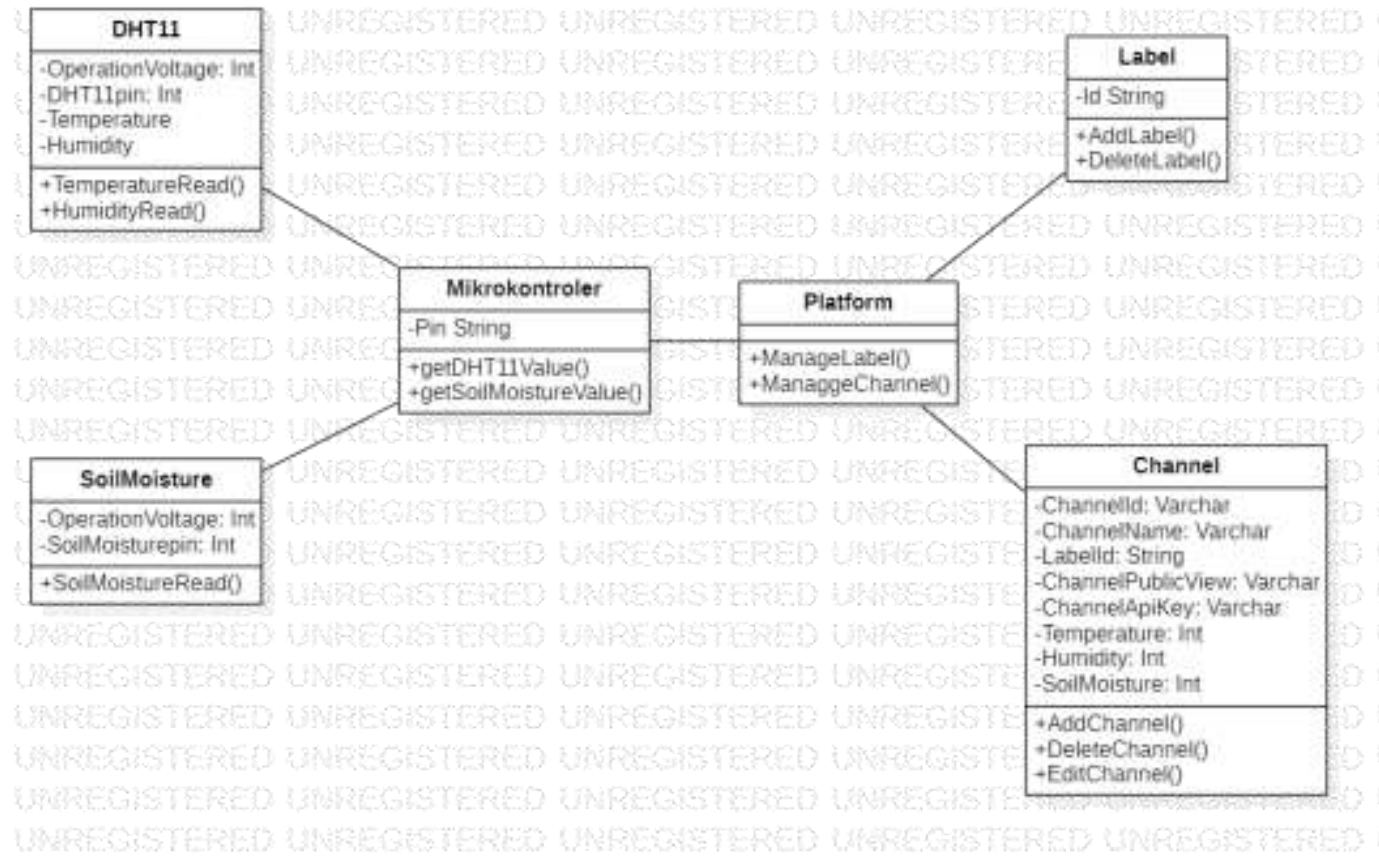

Gambar 3.7 Class Diagram

\subsection{Rancangan Antarmuka}

Rancangan antarmuka dibuat sesederhana mungkin agar user friendly dan tidak membertakan server, mengingat sistem yang penulis buat ini harus memuat data yang banyak. Rancangan antarmuka dibuat menggunakan visio 2013.

1. Antarmuka Login

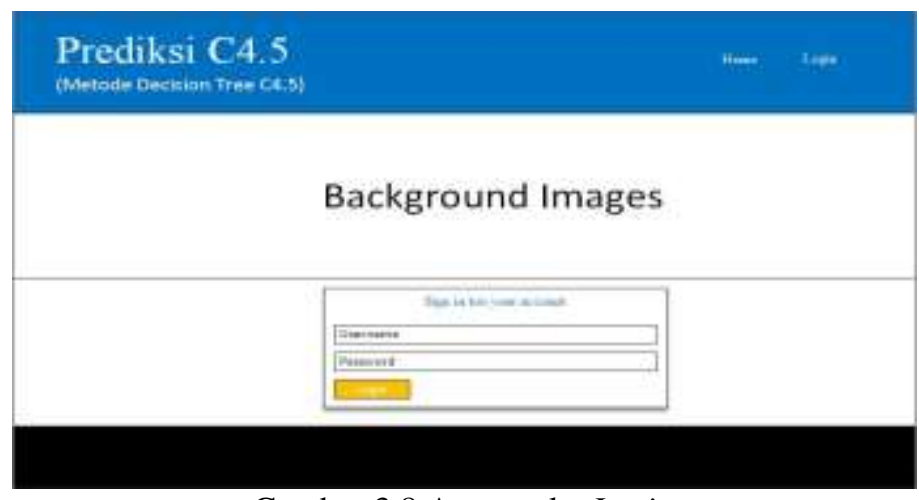

Gambar 3.8 Antarmuka Login 
2. Antarmuka Home

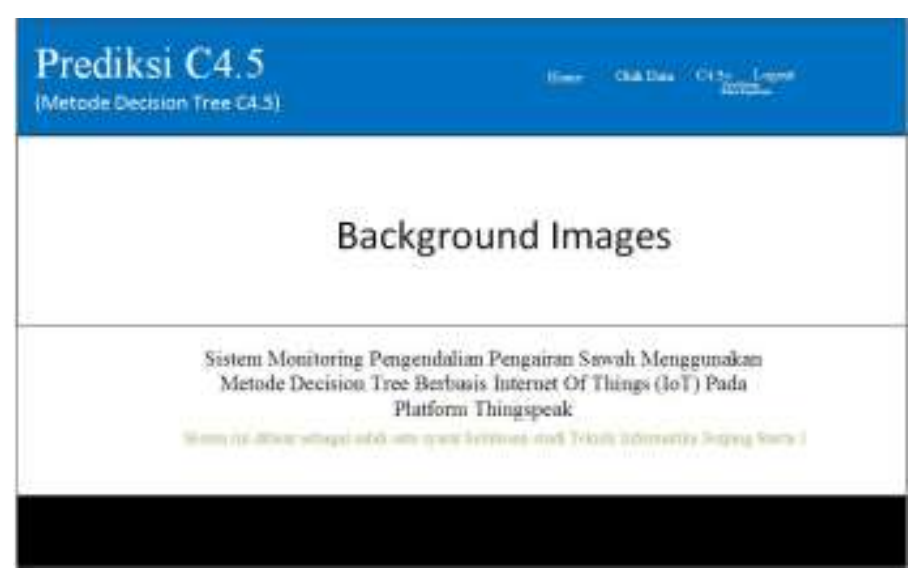

Gambar 3.9 Antarmuka Home

3. Antarmuka Olah Data

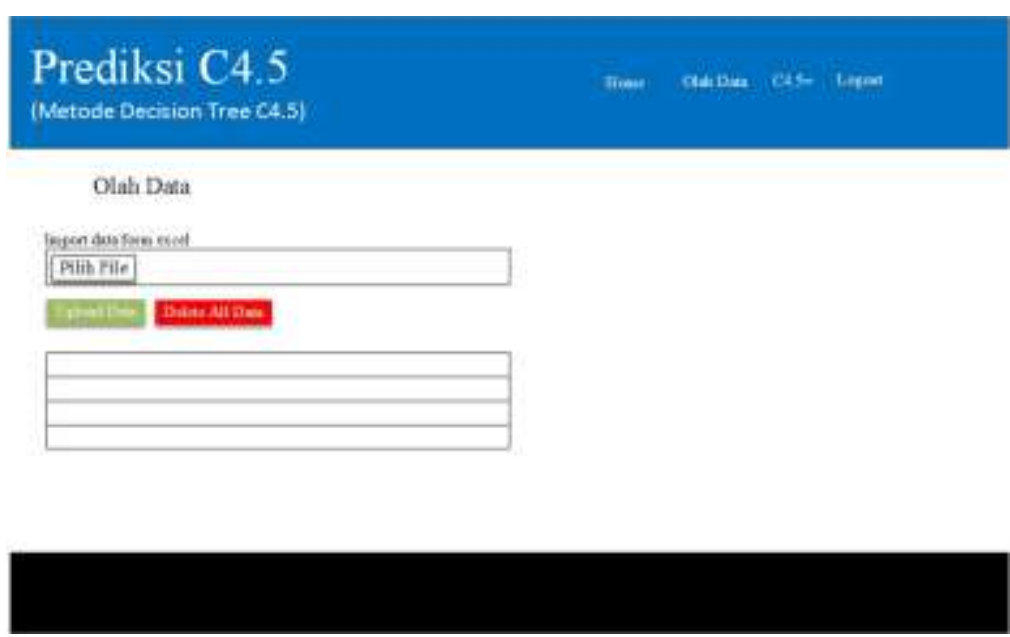

Gambar 3.10 Antarmuka Olah Data

4. Antarmuka Data Mining

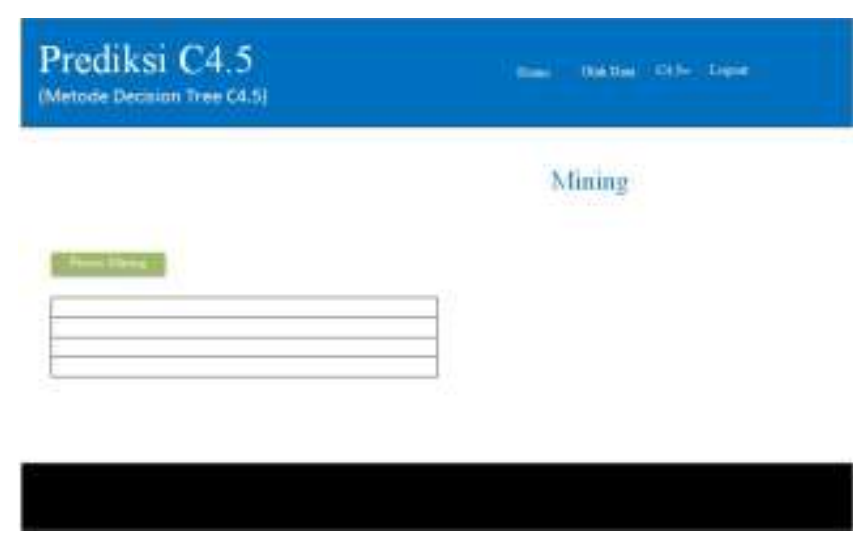

Gambar 3.11 Antarmuka Data Mining 
5. Antarmuka Pohon Keputusan

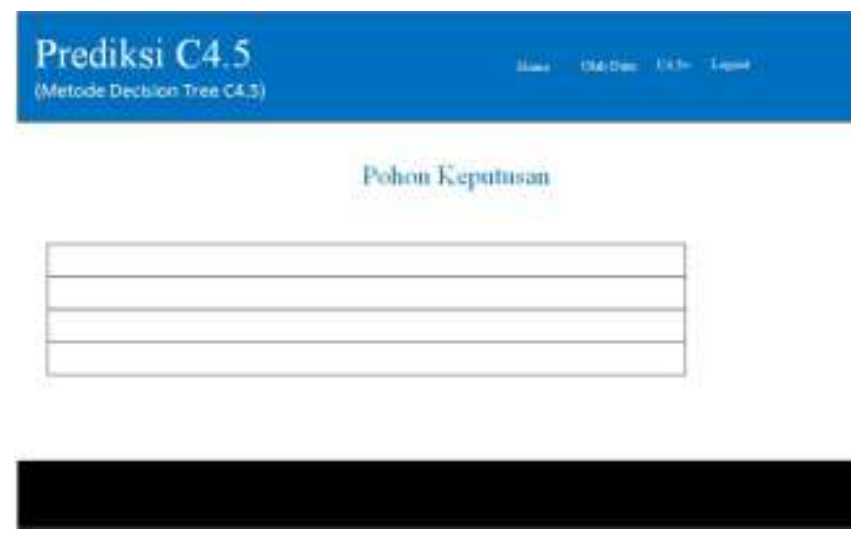

Gambar 3.12 Antarmuka Pohon Keputusan

\subsection{Arsitektur Jaringan}

Sistem penyiraman otomatis ini menggunakan arsitektur jaringan komputer LAN dan menggunakan access point sebagai alat yang digunakan.
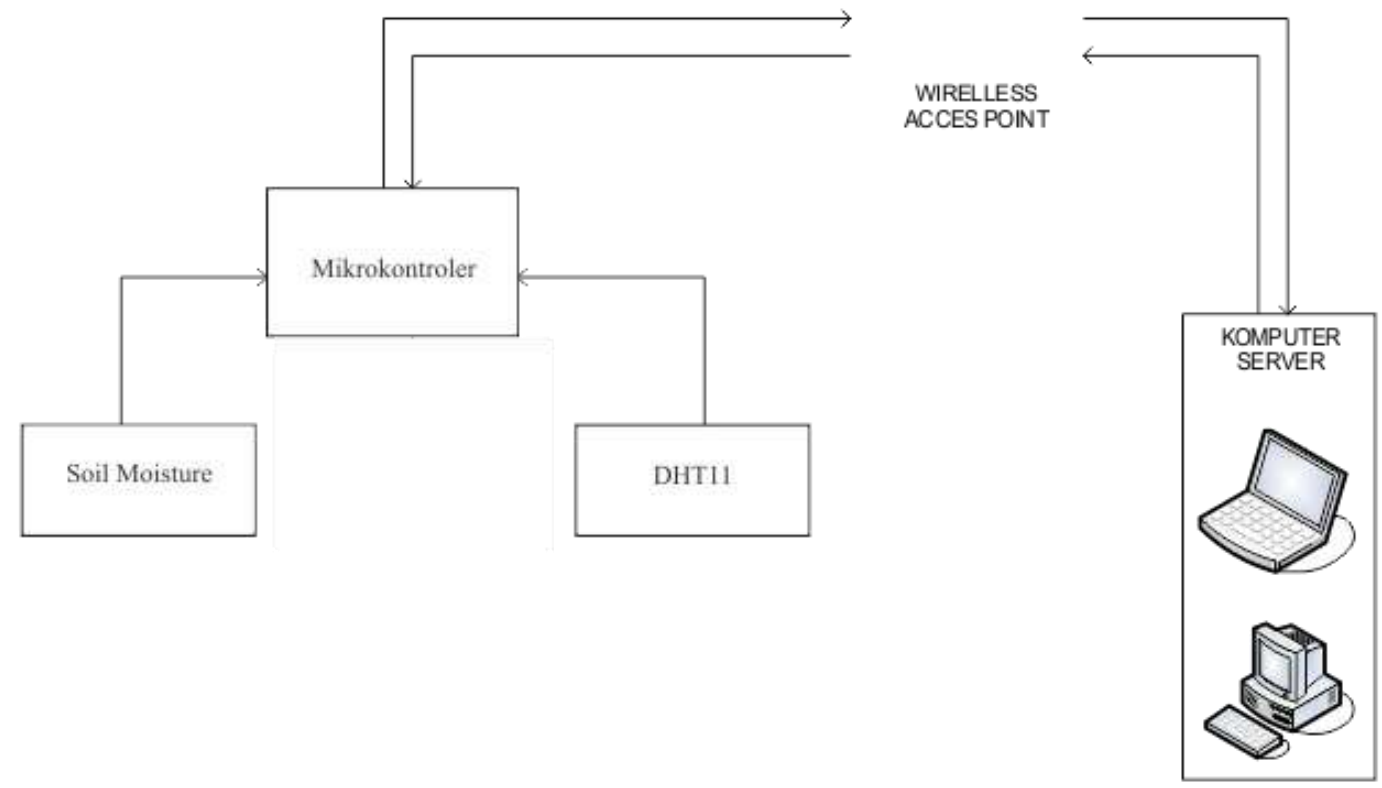

Gambar 3.13 Arsitektur Jaringan

\section{Hasil dan Pembahasan}

\subsection{Implementasi Mikrokontroler}

Pada penelitian ini penulis menggunakan Arduino R3 sebagai board controller, sensor soil moisture untuk membaca parameter kelembaban tanah, sensosr DHT11 unutk membaca parameter kelembaban udara dan suhu modul wifi ESP8266 sebagai alat untuk mengirimkan data parameter dari sensor-sensor, serta perangkat power bank sebagai sumber tegangan agar Arduino tetap berfungsi.

Agar Arduino dan ESP8266 saling terhubung dan sensor dapat berfungsi sesuai dengan yang diinginkan, perlu adanya pemrograman pada board Arduino dan ESP8266, untuk proses kerja alat yang dibuat yaitu Arduino menerima data yang diperoleh dari sensor, kemudian dikirimkan oleh 
Arduino ke ESP8266 yang dikoneksikan dengan jaringan kemudian data dikirim oleh ESP8266 ke komputer server melalui jaringan.

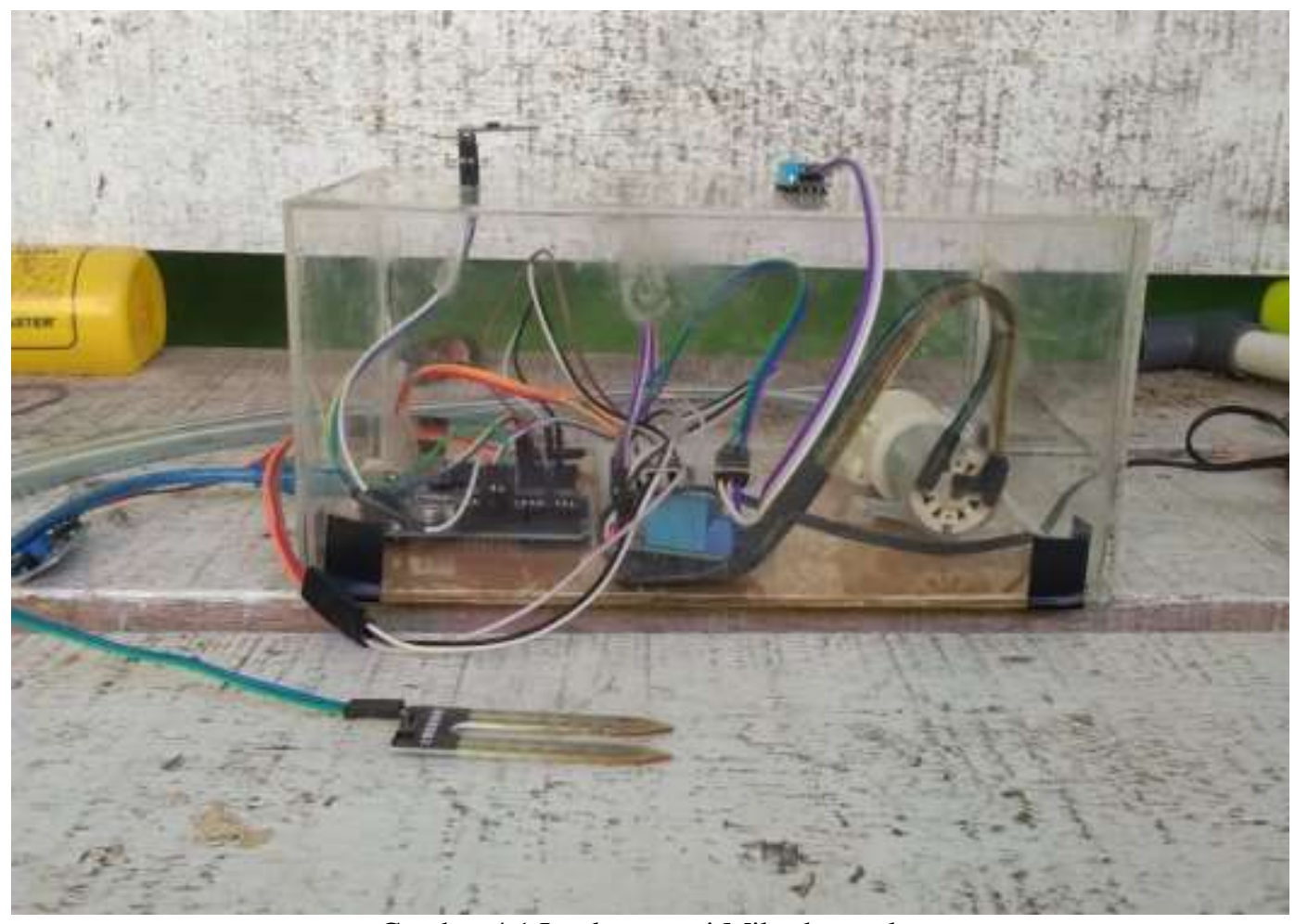

Gambar 4.1 Implementasi Mikrokontroler

Penulis melakukan pemrograman mikrokontroler menggunakan aplikasi Arduino IDE. Proses pemrograman Arduino Uno R3 meliputi proses pemrograman sensor soil moisture dan DHT11. Serta dengan pemrograman untuk proses konfigurasi Arduino dengan ESP8266.

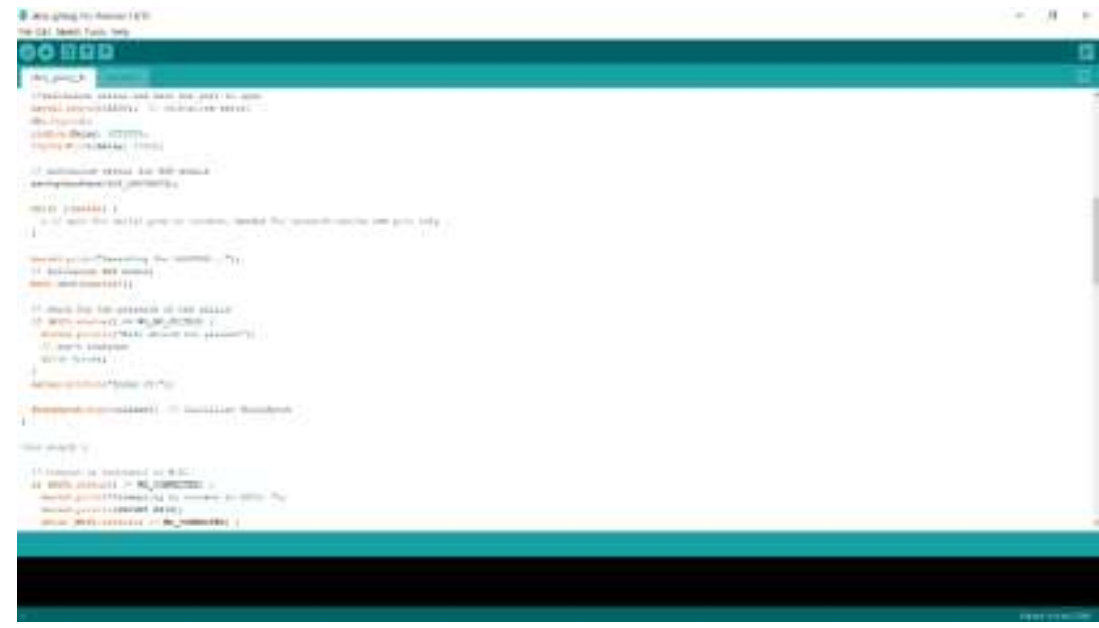

Gambar 4.2 Pemrograman Mikrokontroler 


\subsection{Pengujian Alat}

Tabel hasil pengujian alat merupakan record sistem untuk menguji apakah alat yang penulis buat berjalan dengan baik tanpa error atau tidak.

Tabel 4.1 Pengujian Alat

\begin{tabular}{|c|l|c|}
\hline No. & \multicolumn{1}{|c|}{ Nama Proses } & Hasil Pengujian \\
\hline 1 & Koneksi sensor-sensor ke arduino & Ya \\
\hline 2 & Koneksi ESP 8266 Wifi ke access point & Ya \\
\hline 3 & Koneksi mikrokontroler ke laptop & Ya \\
\hline 2 & Pengambilan data suhu dan kelembaban udara & Ya \\
\hline 3 & Pengambilan data kelembaban tanah & Ya \\
\hline 4 & Pengambilan data volume air sawah & Ya \\
\hline 5 & $\begin{array}{l}\text { Monitoring data dari sensor melalui aplikasi } \\
\text { berbasi android }\end{array}$ & Ya \\
\hline 7 & Koneksi ke Database & Ya \\
\hline
\end{tabular}

\subsection{Implementasi Sistem}

Antarmuka dibuat sesuai sistem dengan rancangan antarmuka yang telah dijelaskan di bab sebelumnya.

1. Halaman Login

Halaman login yang telah penulis buat sesuai dengan rancangan antarmuka sebelumnya. Untuk masuk ke dalam sistem kita harus melakukan login terlebih dahulu dengan memasukan username dan password.
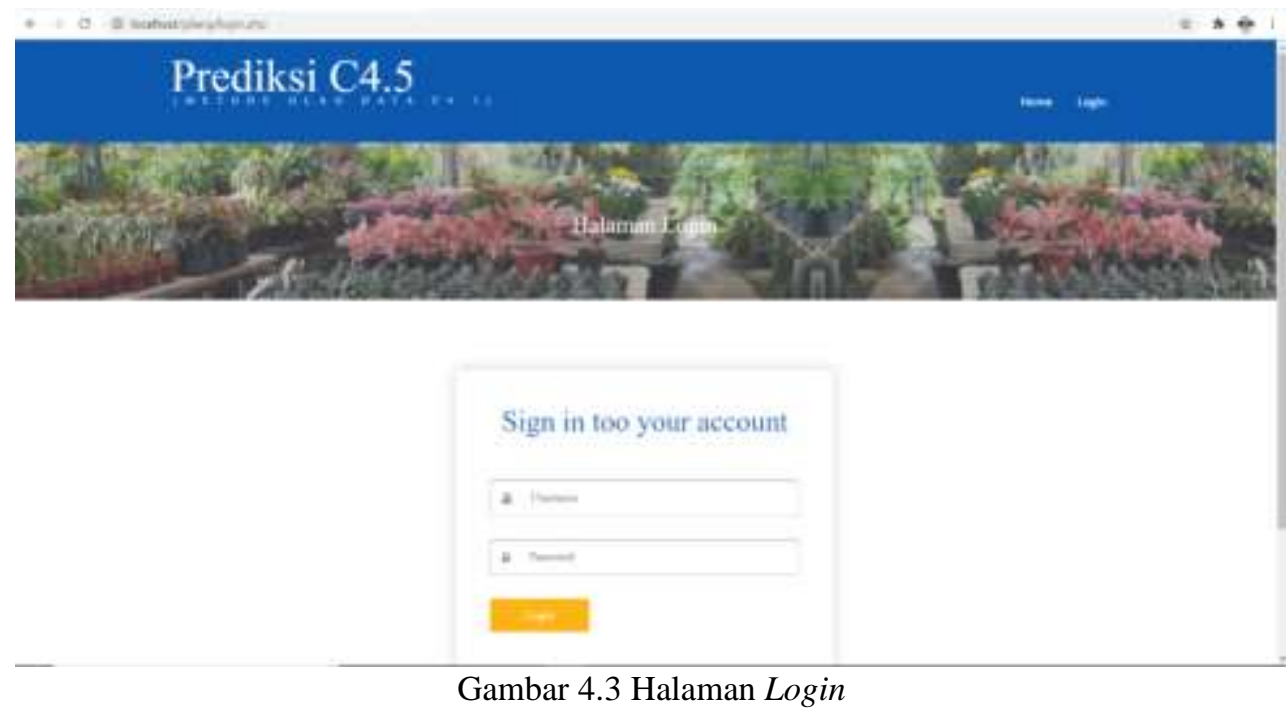

2. Halaman Home

Setelah melakukan login kita akan diarahkan ke halaman utama atau dashboard dari sistem yang berisi informasi tentang sistem. 


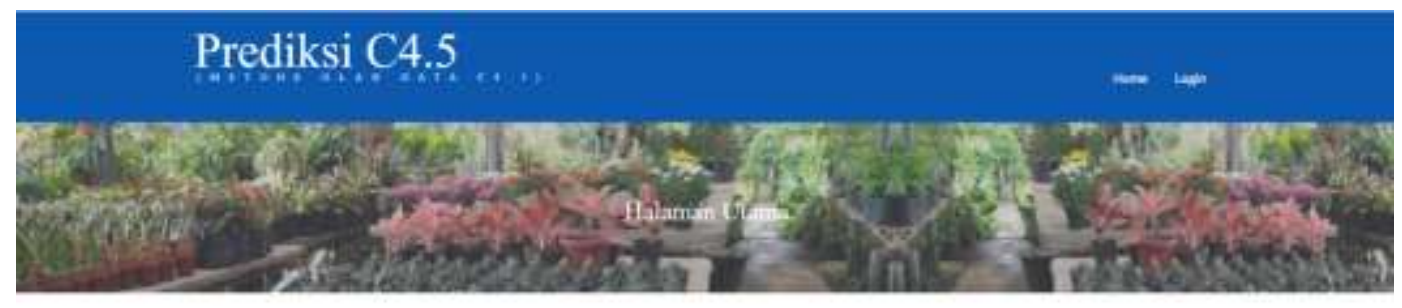

Sistem Monitoring Penyiruman Tanaman Hias Mengyumakan Mstode C45

3. Halaman Olah Data

Halaman ini digunakan untuk upload data latih yang nantinya akan dihitung. Data yang di upload sudah berupa data kategorikal yang sebelumnya telah diubah dari data numeric.

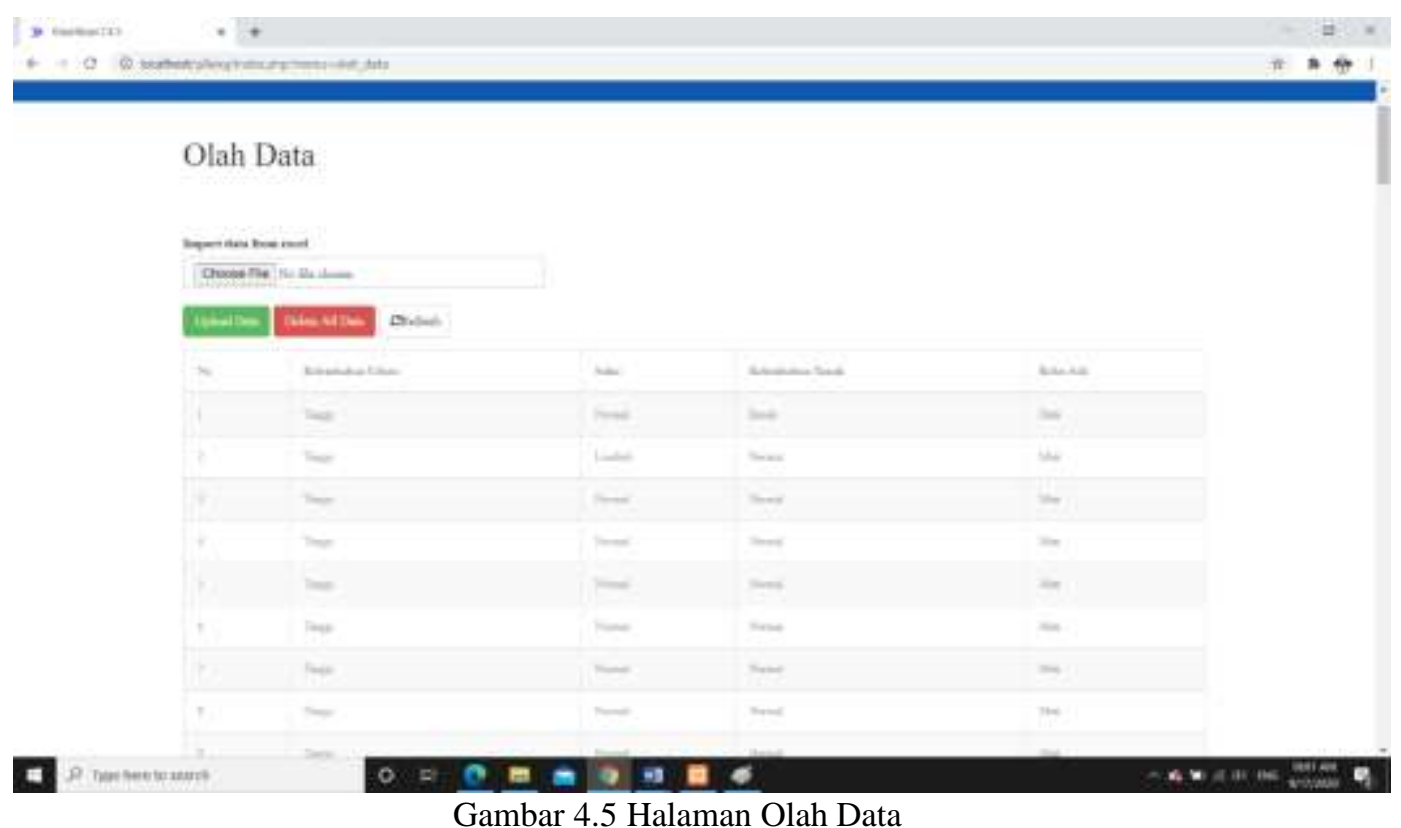

4. Halaman Proses Data Mining

Data yang telah di upload sebelumnya akan tampil pada halaman proses data mining. Pada halaman ini nantinya data akan dihitung dan menampilkan hasil entropy dan gain. 


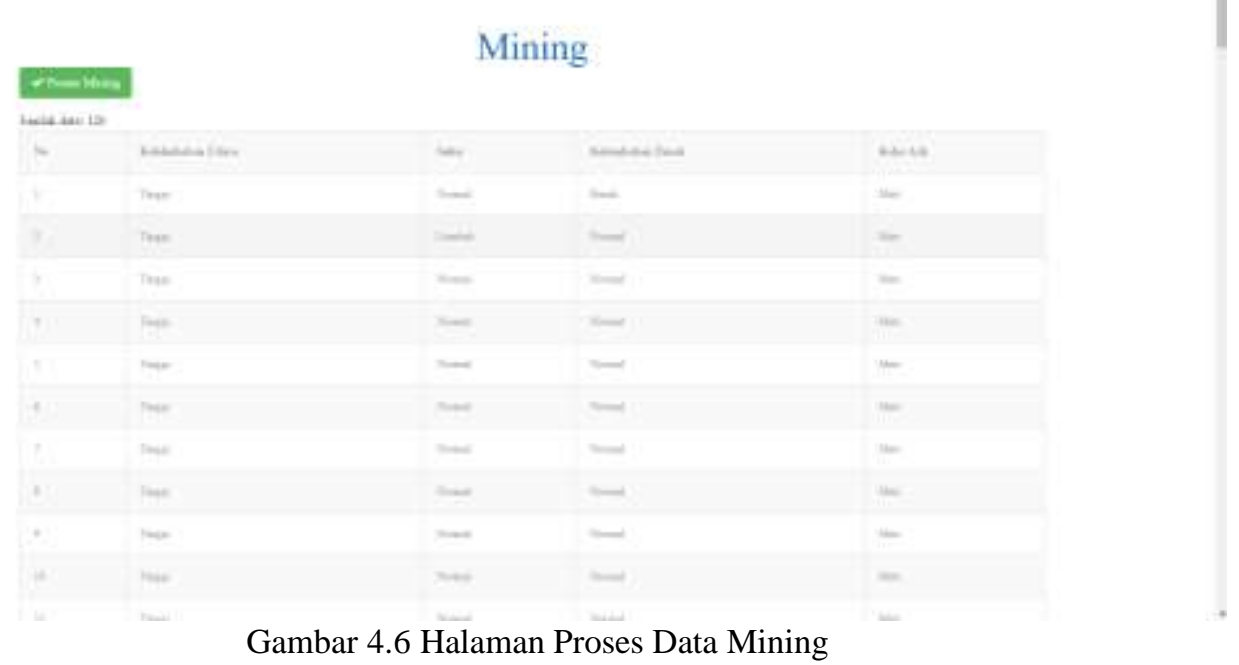

Dengan menekan tombol Proses Mining maka data akan dihitung secara otomatis. Perhitungan ini nantinya menghasilkan beberapa node dan setiap node menunjukan parent dan akar yang nantinya berfungsi sebagai pohon keputusan.

\subsection{Hasil Pengujian Sistem}

Tabel ini merupakan record sistem untuk menguji apakah sistem yang penulis buat berjalan dengan baik tanpa error atau tidak.

Tabel 4.2 Pengujian Sistem

\begin{tabular}{|l|l|l|}
\hline No. & Nama Halaman dan Proses & Hasil Pengujian \\
\hline 1 & Halaman Utama & Ya \\
\hline 2 & Halaman Olah Data & Ya \\
\hline 3 & Halaman Poses Data Mining & Ya \\
\hline 4 & Halaman Pohon Keputusan & Ya \\
\hline
\end{tabular}

\section{Kesimpulan}

Dalam penelitian ini penulis mendapatkan beberapa kesimpulan, diantaranya :

1. Setelah melakukan penelitian ini penulis mendapatkan bahwa dengan adanya alat ini dapat mengurangi terjadinya tanaman hias yang layu/mati, dan juga dapat mempermudah untuk mengontrol tanaman.

2. Penelitian ini dilakukan dengan menggunakan metode $\mathrm{C} 4.5$ yang mana metode ini digunakan untuk melakukan klasifikasi data dengan teknik pohon keputusan

\section{Pustaka}

[1] Yawhe, C. P., Isnawati, \& Aksara, L. F. (2016). Rangcangan Bangun Prototype System Monitoring Kelembaban Tanah Melalui Sms Berdasarkan Hasil Penyiraman Tanaman "Studi Kasus Tanaman Cabai dan Tomat". teknik informatika.

[2] Candra, J. E., \& Maulana, A. (2019). Penerapan Soil moisture sensor untuk Desain System Penyiraman Tanaman Otomatis. SNISTEK.

[3] Putra, H. A. (2018). "Pengertian dan Dasar-dasar dari Mikrokontroler". . https://garudacyber.co.id/artikel/694-pengertian-dan-dasar-dasar-dari-mikrokontroler. 
[4] Shafiudin, S., Rohma, F. J., Prayetya, A. E., \& Firmansyah, R. (2016). Pemantauan Ruang Inkubator Penetasan Telur Ayam Dengan Berbasis Telemetri Menggunakan Arduino Uno R3. Jurnal Nasional Teknik Elektro, 5(1).

[5] Dharwiyanti, S. (2003). Pengantar Unified Modeling Language (UML). Diambil kembali dari RomiSatriaWahono.net: http://romisatriawahono.net. 